\title{
Experiences of Life-Sustaining Treatment Decisions among Patients with Terminal Cancer
}

\author{
Yoon Sun Kim, R.N., A.P.N., Ph.D. \\ Department of Nursing, Dongnam Institute of Radiological and Medical Sciences, Busan, Korea
}

Purpose: The purpose of this study was to examine the life-sustaining treatment decisions of terminal cancer patients. Methods: Data on 10 terminal cancer patients who decided to withhold or withdraw from treatment were collected using in-depth interviews conducted from February 8 to October 30, 2019. Data were collected until saturation was reached and then analyzed using Colaizzi's phenomenological method. Results: In this study, six thematic clusters were identified: "having complicated feelings", "making choices to protect everyone", "accepting and preparing for death", "feeling distress", "pursuing spiritual wellbeing", and "evaluating the new system". Conclusion: When facing death, terminal cancer patients often made choices to protect their family and their dignity with uneasiness of mind when deciding to withdraw from life-sustaining treatments. Though many patients had accepted and prepared for death, they experienced distress about leaving children behind after death. They also pursued spiritual well-being to find peace after deciding to withdraw from life-sustaining treatment. In addition, participants evaluated the new system of policies pertaining to decisions on life-sustaining treatment. Thus, various approaches regarding acceptance and preparation for death, communication with family, hope, and spiritual comfort should be taken in educational interventions to assist terminal cancer patients as they decide whether to withdraw from life-sustaining treatment.

Key Words: Advance directives, Decision making, Neoplasms, Terminal care, Qualitative research
Received December 21, 2020

Revised March 20, 2021

Accepted March 23, 2021

\section{Correspondence to}

Yoon Sun Kim

ORCID:

https://orcid.org/0000-0002-8867-2172

E-mail: cubick3000@naver.com

\section{INTRODUCTION}

\section{Background}

Due to advances in medical technology, most deaths in South Korea occur in medical institutions rather than in private residences [1], according to official annual statistics. The issue of using life-sustaining treatments to prolong life to a meaningless point arose as a topic of civic discourse in Korean society after the Boramae hospital incident in 1997 and later after the 2008 Grandma Kim incident. These incidents resulted in calls for proper policies to mitigate this issue [2], which led to the enactment and enforcement of the Act on Hospice and Palliative Care and Decisions on Life-Sustaining Treatment for $\mathrm{Pa}^{-}$ tients at the End of Life (hereinafter referred to as the Act on Decisions on Life-Sustaining Treatment) beginning on February 4, 2018.

This act provides a legal basis for patients to make the decision to withhold or withdraw from life-sustaining treatment (hereinafter referred to as decisions on life-sustaining treatment). Since the law was enacted, a total of 60,939 terminal patients have prepared life-sustaining treatment plans as of 
February 2021, and the number of terminal patients keeps rising [3]. A terminal patient is defined as a patient for whom fundamental recovery is not possible, whose symptoms are worsening, and whose doctor in charge, along with another specialized doctor in the field, expects death within months despite active treatment efforts [4]. Among terminal patients receiving life-sustaining treatment, cancer patients account for the largest proportion [5].

Decisions on life-sustaining treatment are a tremendously specific, existential, and individual experience for patients who suffer from terminal cancer. In the process, patients undergo different internal and external struggles including changing perceptions of life-sustaining treatment and conflicts with family members regarding decisions on life-sustaining treatment [6]. Therefore, to help patients with terminal cancer who experience complex internal and external conflicts, it is necessary to provide sufficient education and support to help them make the right decision for them regarding life-sustaining treatment [6]. Most previous studies, however, are quantitative studies, including surveys about the awareness of patients, family members, and medical professionals of decisions on life-sustaining treatment $[7,8]$ and studies on proxy decisions by family members for patients who are incapable of making decisions themselves [9]. In addition, qualitative studies, which can provide a foundation for education and psychological nursing interventions for terminal patients to support their decisions on life-sustaining treatment, are insufficient. Quantitative studies and statistical analyses are also limited when it comes to providing a full understanding of the unique situations and myriad internal struggles terminal cancer patients face when making decisions on life-sustaining treatment. Therefore, this study aimed to be comprehensive in scope in order to provide a more accurate impression of the experiences of terminal cancer patients when making decisions on life-sustaining treatment. Phenomenological studies emphasize lived experience as recognized and interpreted by a participant and aim to treat an individual's reported conscious experience as an ample description of external reality [10]. Thus, a phenomenological approach was useful for the purposes of this study and phenomenological methodologies were employed to identify and classify essential semantic structures related to decisions on life-sustaining treatment in order to attain a more in-depth understanding of terminal cancer patients' experiences.

\section{Purpose}

This was a descriptive study that used phenomenological methodologies to gain an in-depth understanding of the experiences of terminal cancer patients by identifying and classifying essential semantic structures related to decisions on lifesustaining treatment. Its aim was to collect data that would provide basic materials for the development of interventions to help terminal cancer patients make these decisions.

\section{METHODS}

\section{Study design}

This study aimed to identify essential semantic structures related to decisions on life-sustaining treatment after studying the experiences of terminal cancer patients. This study used the phenomenological method described by Colaizzi [10] to explore the fundamental properties of subjective human experiences to facilitate total and in-depth understanding. A phenomenological study attempts to understand the raw and real experiences of an individual and analyze the content of those experiences using inductive reasoning. By examining the personal, subjective, and relative experiences expressed in language by terminal cancer patients making decisions on lifesustaining treatment, the essence of their experiences can be derived from their statements using creative intuition and generalized to comprehensively describe subjective phenomena.

\section{Participants}

The participants in this study were patients diagnosed with terminal cancer at D institute located in B metropolitan who had made a decision regarding life-sustaining treatment. Purposive sampling was used to select participants who understood the policies related to decisions on life-sustaining treatment and who could provide the most in-depth accounts of their experiences making decisions on life-sustaining treatment. The researcher at D institute who was in charge of counseling related to decisions on life-sustaining treatment selected the study participants. Then, among the patients who 
agreed to participate in the study, those who could freely express their thoughts, had no issues with cognitive functions, and were healthy enough to participate in a 1-hour interview were selected.

\section{Data collection}

Data were collected until the data set reached saturation, which occurred after interviewing the eighth participant. The collection period was from February 8, 2019, to October 30, 2019. Data were collected using individual in-depth interviews. Interview sessions began after the researcher fully $\mathrm{ex}^{-}$ plained the purpose of the study and data collection method to the participant. After confirming that the participant understood the explanation, a written consent form was completed by the participant and the session commenced. To ensure uninterrupted and free expression by participants and protect personal information, each interview session was conducted in the counseling room of D institute. Participants were interviewed for one or two sessions lasting 30 minutes to 1 hour each depending on the participant. The researcher began the interview with lighter topics about daily routines, then gradually moved into topics related to the study. The researcher created an easygoing atmosphere and tried to actively listen, avoiding abrupt interruptions or judgments about what the participant was saying.

The interview consisted of a core question ("How would you describe your experience making decisions on life-sustaining treatment?") and multiple supplementary questions ("How did you feel when you were diagnosed with a terminal disease?”, "How did you reach the decision to withdraw from lifesustaining treatment?", "How do you feel now after you decided?", and "What did you wish for in the process of making a decision?"). The questions were mostly open-ended and unstructured. Each interview session was recorded using a voice recorder and phone after receiving the participant's consent. Data were collected and analyzed simultaneously until the data set was saturated. Recorded statements were listened to repeatedly and transcribed by the researcher. Uncertainties were addressed in subsequent interview sessions with participants by confirming details. Observations made during the interview about the participant, the session's atmosphere, the participant' $s$ attitude, and the researcher's impressions were also recorded.

\section{Data analysis}

Data were analyzed using the six-step phenomenological analysis method by Colaizzi [10]. First, the researcher conducted in-depth interviews with each participant, then directly transcribed their statements into text after repeated listens. During this first step, the researcher tried to empathize with participants in every sense and maintain full awareness of participants as holistic human beings, rather than simply recording what participants said. Second, the researcher extracted significant sentences and phrases related to phenomena of interest after repeatedly reading and highlighting the transcripts. Third, the researcher identified universal and abstract semantic units from significant phrases and sentences and confirmed using raw data if the structured semantic units clearly articulated each participant's experience. Fourth, the researcher categorized the significant statements, divisions, and collections of topics and subjects based on the structured semantic units. Fifth, the researcher re-read the participants' individual accounts from the first step while considering the comprehensive results of analysis up to that point to reaffirm the accuracy of the significant statements before making a final description of the phenomena. Sixth, the researcher approached the participants again in order to confirm that the final description and essential structures of their experiences corresponded with their actual experiences. Referencing the findings of the study, the researcher quickly read the transcribed resources on each participant from the beginning to confirm that the results reflected the participant's experience. The researcher then presented the findings to two of the participants to verify that the derived results aligned with the participants' experiences. Throughout the entire process of data analysis, the researcher was conscious of Husserl's description of 'epoché' [11], meaning that the researcher suspended judgment regarding study subjects and avoided being biased by her thoughts, feelings, and perspectives. Through this process, the researcher strived to avoid distortion, omission, or exaggeration resulting from biases related to the study participants.

\section{Rigor of the research}

The quality of the study was guaranteed by applying the criteria for credibility, fittingness, auditability, and confirmabil- 
ity described by Guba and Lincoln [12]. In order to establish credibility, the researcher strived to maintain a neutral attitude by bracketing previously held prejudices and stereotypes so that her thoughts did not impact the process of the interviews and analysis. Since the researcher had extensive experience providing counseling about decisions on life-sustaining treatment, there were opportunities for the researcher to observe and understand the psychological state of terminal patients in the process of making a decision on life-sustaining treatment. Thus, the researcher was able to refrain from hastily judging the participants' circumstances. The procedures suggested by Colaizzi [10] were faithfully observed to ensure fittingness of the analysis. The results were then confirmed by participants through interviews and phone calls. Demographic characteristics of the participants and characteristics related to the diseases from which they were suffering were provided. Processes and procedures undertaken during research were documented in detail to ensure auditability. In addition, the original $\mathrm{re}^{-}$ sources that formed the basis for our analysis were cited as references. Finally, confirmability was achieved by establishing creditability, fittingness, and auditability to reduce bias and maintain neutrality [13].

\section{Establishing researcher sensitivity}

The researcher developed an overall understanding of qualitative research through academic conferences and qualitative methodology courses while in graduate school, thus establishing sensitivity. The researcher also has had a qualitative research article published in an academic journal. Moreover, extensive hands-on experience with life-sustaining treatment has given the researcher a deep understanding of the process of patients making decisions on life-sustaining treatment. To exclude the possibility of bias, patients for whom the researcher provided counseling were ruled out as potential participants for data collection. The participants were recruited through referrals by nurses in wards and outpatient nurses. In addition, the researcher made an effort to bracket any prejudices related to decisions on life-sustaining treatment by recording personal thoughts prior to entering the data collection process. During analysis, the researcher strived to illustrate the essence of the phenomena experienced and described by participants. The researcher's approach was to concentrate on the essence of participants' experience using epoché.

\section{Ethical considerations}

This study was approved by the institutional review board at $\mathrm{D}$ institute in B metropolitan city (Approval number: D-1901-014-022). To protect the rights of research participants, the researcher conducted interviews only after explaining the purpose and methods of the research to participants and obtaining their voluntary written consent. Participants were notified that they could withdraw from the study at any time without consequence. The researcher also explained to participants that anonymity was ensured so they could freely engage in the interviews and that the contents of interviews would only be used for academic purposes. Moreover, participants were notified that collected data would be stored under double locks and would be disposed of after completion of the study. All participants were given a small monetary gift as compensation.

\section{RESULTS}

\section{Experiences of terminal cancer patients related to decisions on life-sustaining treatment}

Using descriptive data from in-depth interviews with 10 terminal cancer patients who had experience making decisions on life-sustaining treatment, the researcher constructed a semantic framework for decision-making experiences using Colaizzi's [10] phenomenological methodology.

There were ultimately 10 participants, with a mean age of 68.7 years old and an age range of 61 to 75 years old. Six were male, and four were female. Eight were diagnosed with liver and biliary tract cancer, and two were diagnosed with lung cancer. Six participants were receiving supportive treatments, and the remaining four were going through palliative chemotherapy without surgery. After analysis, six thematic clusters were identified. They included: "having complicated feelings", "making choices to protect everyone", "accepting and preparing for death", "feeling distress", "pursuing spiritual wellbeing", and "evaluating the new system". These thematic clusters included 13 themes, 34 meaning units, and 72 structured semantic units (Table 1). 
Table 1. Thematic Clusters and Themes of Experience Related to Life-Sustaining Treatment Decisions among Terminal Cancer Patients.

\begin{tabular}{|c|c|c|}
\hline Thematic cluster & Theme & Meaning unit \\
\hline \multirow[t]{6}{*}{ Having complicated feelings } & \multirow[t]{2}{*}{ 1. Shaken up } & $\begin{array}{l}\text { 1) The end-stage condition was expected, but they still had mixed } \\
\text { feelings }\end{array}$ \\
\hline & & 2) Emotional difficulty \\
\hline & \multirow[t]{2}{*}{ 2. Regret for unattempted treatment } & 1) Regret about treatments that were not attempted \\
\hline & & 2) Regret about not having taken care of their health in life \\
\hline & \multirow{2}{*}{$\begin{array}{l}\text { 3. Not wanting to burden others by } \\
\text { choosing life-sustaining treatment }\end{array}$} & 1) Did not want to burden family with caregiving needs \\
\hline & & 2) Worried that the children would be financially impacted \\
\hline \multirow{7}{*}{$\begin{array}{l}\text { Making choices to protect } \\
\text { everyone }\end{array}$} & \multirow{4}{*}{$\begin{array}{l}\text { 1. The wish to be respected as a human } \\
\text { being until the end }\end{array}$} & 1) Wished to maintain dignity until the end \\
\hline & & 2) Did not wish to unnaturally prolong life \\
\hline & & 3) Wanted to die cleanly \\
\hline & & 4) Wanted to die comfortably \\
\hline & \multirow[t]{3}{*}{ 2. Choice for the family } & 1) Did not want to mentally and financially burden children \\
\hline & & $\begin{array}{l}\text { 2) Based choices on past family experience with life-sustaining } \\
\text { treatment }\end{array}$ \\
\hline & & 3) Made one's own decision in advance \\
\hline \multirow{6}{*}{$\begin{array}{l}\text { Accepting and preparing for } \\
\text { death }\end{array}$} & \multirow[t]{3}{*}{ 1. Accepting death } & 1) Accepting one's own health status \\
\hline & & 2) Recognizing death as a natural process \\
\hline & & 3) Not having regrets in life \\
\hline & \multirow[t]{3}{*}{ 2. Preparing for imminent death } & 1) Reflecting on past life \\
\hline & & 2) Re-establishing relationships with others \\
\hline & & 3) Living for oneself \\
\hline \multirow[t]{4}{*}{ Feeling distress } & \multirow[t]{2}{*}{ 1. Saddened by the expected goodbye } & 1) Feeling pressed for time after making the decision \\
\hline & & 2) Feeling sorry for leaving family behind \\
\hline & \multirow[t]{2}{*}{ 2. Growing concern for children } & $\begin{array}{l}\text { 1) Feeling concerned about children after deciding on life-sustaining } \\
\text { treatment }\end{array}$ \\
\hline & & 2) Feeling sorry for children \\
\hline \multirow[t]{5}{*}{ Pursuing spiritual well-being } & \multirow[t]{2}{*}{ 1. Not losing hope } & 1) Feeling determined to overcome the disease \\
\hline & & 2) Trying to find peace \\
\hline & \multirow[t]{3}{*}{ 2. Relying on faith } & 1) Being consoled by religion \\
\hline & & $\begin{array}{l}\text { 2) Showing gratefulness for their relative comfort despite their health } \\
\text { status }\end{array}$ \\
\hline & & 3) Relying on faith to resolve the fear of death \\
\hline \multirow[t]{6}{*}{ Evaluating the new system } & \multirow[t]{3}{*}{ 1. Feeling the need for the system } & 1) Showing gratitude after being introduced to the system \\
\hline & & 2) Trusting in the national system \\
\hline & & 3) Being willing to use this system \\
\hline & \multirow[t]{3}{*}{ 2. Shortcomings of the system } & 1) Being frustrated by the lack of promotion of the system \\
\hline & & 2) Having difficulty accessing the system \\
\hline & & 3) Insufficient education on life-sustaining treatment decisions \\
\hline
\end{tabular}

\section{1) Thematic cluster 1. Having complicated feelings}

The first thematic cluster, "having complicated feelings", includes three themes: "shaken up", "regret for unattempted treatment", and "not wanting to burden others by choosing life-sustaining treatment". These reflect the psychological undertakings of participants from when they were diagnosed with a terminal illness and when they are later faced with a decision on life-sustaining treatment. They often experienced a psychological struggle related to the fact that their condition would not improve, with some questioning it. Furthermore, they expressed regret about treatments they could have tried but did not. Some regretted not taking care of their health in the past. Nevertheless, they did not want to impose burdens on their families and friends by meaninglessly extending their lives. 


\section{(1) Theme 1. Shaken up}

Participants tended to experience anguish when their doctors suggested that further treatment would be ineffective and that they should decide on life-sustaining treatment. While they typically understood that the prognosis was not very good, having a doctor confirm it in person resulted in complicated feelings. Many participants said that it was emotionally difficult for them to feel their mortality becoming a reality.

Ah $\cdots$ It was kind of complicated. Like, finally, the time has come, so now we have to accept our death. So then I feel like, "Is this it?" and it's so surreal and absurd. It felt like everything collapses when doctors say that this thing doesn't work, that thing doesn't work $\cdots$ Nothing does seem to work. (Participant 2)

\section{(2) Theme 2. Regret for unattempted treatment}

Participants told the researcher that they began to think a lot when they learned there was nothing doctors could do to treat them. They contemplated whether their condition was really uncurable, or whether there were alternative treatments. They also expressed frustration and regret about other treatments that they did not try, and that their present health condition may have been a result of bad management of their health in the past.

I was thinking that I wasn't in good shape, but when my doctor said so, I began to think if what he said was real. Even while I am saying to myself, "He is right, he is right,' but then I think "Is there any other way?" while I kind of walk around places to places.' I think about whether I should find different doctors, or try some sort of alternative remedies other people are talking about. (Participant 3)

I didn't know it would come to this. I just lived, as usual, thinking that everything's gonna be alright, but now I feel that it might have been different if I had managed my health better. (Participant 5)

(3) Theme 3. Not wanting to burden others by choosing lifesustaining treatment

Participants wanted to avoid imposing psychological and economic burdens on their families and children by meaninglessly extending life-sustaining treatment. They were worried about burdening their families up until their final moments.

Even though I am sick, it's my first wish not to give my children and friends a hard time and taking care of myself before I pass. (Participant 1)

\section{2) Theme cluster 2. Making choices to protect everyone}

The second thematic cluster, "making choices to protect everyone", comprises two themes: "the wish to be respected as a human being until the end" and "choice for the family". Participants decided on life-sustaining treatment for themselves and for all their family members. They wanted to approach their last moments peacefully and with dignity, and they did not want a prolonged, painful life. Participants also often expressed that they made decisions based on not wanting to impose burdens on their families.

\section{(1) Theme 1. The wish to be respected as a human being until the end}

Participants rendered decisions on life-sustaining treatment for themselves. They wanted to protect their dignity until the end and, for those reasons, they refused forced extension of life. Participants also wanted their last moments to be painless and comfortable, and they tended to want hospice care.

For myself, I don't want to be seen as ugly all the way up to the last moment. My father had such a strong, proud personality, but when my father was suffering from cancer after it recurred, he couldn't (physically) close his eyes, and his friends from the church came to visit him and saw all that '. I didn' t like it, and I don't want people to see me like that, and It would be painful to let my kids see that. (Participant 3)

Whenever I see someone lying down on the bed who can't even move, I don't want to live like that. It feels like my value diminishes.. As they say, I want a dignified death. My mind will be clear when I go. If I could move it would be great, but if that doesn't happen, I don't think I would feel like myself. (Participant 5) 
Other patients say that, when the moment comes, it is so painful. Well, in that case, I'd rather pass $\cdots$ That's the way things should be. The thing I am afraid of the most is pain. (Participant 6)

\section{(2) Theme 2. Choice for the family}

All of the participants wanted not to impose mental or eco- $^{-}$ nomic burdens on their children by choosing life-sustaining treatment. Participants who had experiences with family members receiving life-sustaining treatment decided to withdraw from it. Participants also felt that such decisions should be made when their minds were clear in order not to burden their families later.

When children look at their parents, how upset would they feel, and how strained would they be mentally and financially? I don't want them to carry that. Even if I die after paying all my bills myself $\cdots$ You know people say that long illness even wears out good children's love'. How would they feel when it comes to the point where a daughter feels, even deep down, wishes her mother would be gone now? When you are lying down on the bed you don't know anything $\cdots$ and I am saying that I wouldn't want to lie down that long... (Participant 3)

My father had some liver problems, so it hasn't been even a year. He was old, and even though we are his children, we gave up on keeping him alive. So I have seen that and stuff, so I decided for myself this time around. (Participant 2)

I should get it sorted out when my mind is clear, I should do it myself, I don't want to have my kids make that decision for me. So I think it is better to do it myself when it is not too late. (Participant 1)

\section{3) Theme cluster 3. Accepting and preparing for death}

The third thematic cluster, "accepting and preparing for death", includes two themes: "accepting death", and "preparing for imminent death". This thematic cluster demonstrates that participants were in the process of accepting their mortality in their current state and were preparing for death.

\section{(1) Theme 1. Accepting death}

Participants wanted to be mindful of their current state of health and tried to act in accordance with the natural order. They expressed that they did not have unresolved regrets about life upon deciding not to undergo life-sustaining treatment.

I thought, it's the end, and I accepted it quietly $\cdots$ What can I do? There is nothing I can do. I accepted it silently, thinking that it is the end of the line for me. (Participant 2)

You have to take what you get from nature.. If I get treatment, would I live five more years? Ten? It's not meaningful at all, is it? So '. As people say, you came from the earth, so you return to the earth. I bide my time and follow my fate. (Participant 4)

\section{(2) Theme 2. Preparing for imminent death}

This theme refers to participants' preparations for death after making a decision on life-sustaining treatment. They looked back on the paths their lives took, trying to look back on relationships with family and friends ahead of mortality, then proceeded to examine those relationships on a more spiritual basis. Moreover, they decided to live for themselves during whatever time they had left, and they were resolute in acting on that decision.

When a person gets a death sentence, it makes me look back how I have lived, and I tend to think more $\cdots$ (Participant 6)

So, you know, you talk shit about other people when we meet up with friends. After I know I am dying, I stopped doing that. I am going to God's heaven soon, so I should not sin anymore. There's not much time, not much time. They are the apples of my eyes, so I try to treat them better while I still can. I need to treat them really well, so I don't hurt them and they don't hurt me. (Participant 7)

I am trying to do good things from now on. I go out and have some good meals for myself and stuff. (Participant 6)

\section{4) Theme cluster 4. Feeling distress}

The fourth thematic cluster, "feeling distress", includes two 
themes: "saddened by the expected goodbye" and "growing concern for children". This thematic cluster shows that, even though participants made decisions on life-sustaining treatment, they still had lingering burdens in their minds which would go unresolved to the end. Since participants had to part with their families, and they could not help worrying about their children's fates after they are gone, these burdens stayed within their psyches, resulting in internal struggles.

\section{(1) Theme 1 . Saddened by the expected goodbye}

As participants began to clearly understand that they would be parting with their families soon, they became more anxious about the family members they were leaving behind and felt sorry for them.

When I made my decision, I thought about stuff. I couldn't bring it up to my caregiver because I don't want to shock them or.' If I die, I am sorry about my parents, because they are still there $\cdots$ It's the most challenging bit. (Participant 2)

\section{(2) Theme 2. Growing concern for children}

Participants said that they let go of many burdens from their minds when they accepted their situation and made a decision on life-sustaining treatment. However, their concerns for their children only grew, and they felt sorry for making their children's lives hard after they got sick.

When I cry by myself, I don't cry because of me, I always cry because of my kids. When I die, they will grow old, how would they grow old? Death didn't really creep up on me because I didn't have much experience with my family members dying. But when it comes to me, when I am sick, I think about my kids a lot. (Participant 3)

Well, I feel a bit sad doing this interview. First of all, I feel really sorry about my kids... I couldn't do anything for them other than being sick $\cdots$ How would they live on without me? (Participant 4)

\section{5) Theme cluster 5. Pursuing spiritual well-being}

The fifth thematic cluster, "pursuing spiritual well-being", comprises two themes: "not losing hope" and "relying on faith". This cluster shows that participants held onto the hope of recovery once again after making a decision on life-sustaining treatment and tried to find peace by relying on faith to overcome the fear of death.

\section{(1) Theme 1. Not losing hope}

Even when participants chose to withdraw from life-sustaining treatments, they still had the will to overcome their diseases. However, this did not mean curing the disease, but rather it was an expression of hope that they would try to live through it. They pursued comfort in their minds by using that strategy.

I decided on it, but life-sustaining stuff is about when I am going to die, and I still think I would get through my disease. Anyway, I will get over this. So I don't think yet I am losing this battle. I still think I will win. I will not lose hope. (Participant 2)

It was emotionally difficult. But I tried to feel comfortable about it. If I feel comfortable, my body might get better. (Participant 4)

\section{(2) Theme 2. Relying on faith}

Participants were comforted by their religious beliefs or faith while navigating their challenging situations. They expressed gratitude for their relative comfort given their health condition. However, they were also aware that death was not far away and tended to rely on a higher power to address their fears related to death.

I believe I should be grateful compared to other people. You know, some people pass away while lying in bed all the time. For me, I can work, and I can go back and forth from my home to the hospital, so I am greatly blessed. (Participant 4)

I don't want to be in pain when I die. However, I feel comfortable when I am beside God. So I am not afraid of dying. You wouldn't imagine the power of faith. (Participant 7)

\section{6) Theme cluster 6. Evaluating the new system}

The sixth thematic cluster, "evaluating the new system", 
includes two themes: "feeling the need for the system" and "shortcomings of the system". This thematic cluster accounts for participants' evaluations of policy processes related to decisions on life-sustaining treatment. While participants showed sympathy and trust in the necessity of the structured system, they also expressed frustration and talked about how the system could improve.

\section{(1) Theme 1. Feeling the need for the system}

Participants said that when they learned about the system governing decisions on life-sustaining treatment, they sympathized with the policy-makers' intentions and had high regard for the state's attempts to establish the system.

When I saw the poster about this life-sustaining treatment policy at the hospital hallway, I thought it is a good policy, and it worked well for me when I tried to go through it. I think the state is doing a good job setting up these systems. (Participant 1)

A priest knew another priest whom he looked up to. When the other priest got old and went to near death, the two priests talked and agreed that "Hey, when we go, let's do away with the whole life-sustaining treatment thing". They talked to each other. So one time one of two priests really got bad, close to death, and the hospital said that what is agreed on verbally is not enforceable. Then, this priest got punctured in his neck at the hospital and it was a horrendous scene. So the other priest said that verbal agreement doesn't do anything, so you have to write things down, then I went, "Yes, I need to make the decision". (Participant 7)

\section{(2) Theme 2. Shortcomings of the system}

Most participants became aware of policies related to decisions on life-sustaining treatment through their doctors, and they felt that more explanation of the system was needed. Some participants heard of the system through promotion campaigns via media outlets, but they did not know how to go about making the decision when they tried to do it later on.

So, when I tried to do some research on the stuff, where should I go to get more information? I needed to ask about it to my daughter, but it's not a really pleasant topic to talk about it with her, and I didn't want to learn how to use the computer, so I was like, “Where should I go?” (Participant 3)

Another way of looking at it is that even though this decision is so huge in a person's life, but the explanation seems rather brief. When you face the situation, you have tons of things to think about, and endless concerns. Anyway, I guess the decision should be made by the patient at the end of the day. (Participant 2)

\section{DISCUSSION}

The six thematic clusters in this study were "having complicated feelings", "making choices to protect everyone", "accepting and preparing for death", "feeling distress", "pursuing spiritual well-being", and "evaluating the new system". This study's main purpose was to identify and examine the clusters of themes that made up the structures of experience related to decisions on life-sustaining treatment for terminal cancer patients.

First, "having complicated feelings" indicates that participants felt an emotional disturbance as well as regret and frustration about their past treatment decisions. However, participants were also reluctant to impose burdens on other people close to them. These experiences align with the results from other domestic and international studies [14-16], in which many patients and their families felt regret about past treatment decisions as well as psychological stress when deciding to withdraw from life-sustaining treatment. Brehaut et al. [17] suggests that decisions on life-sustaining treatment are likely followed by regret about the decision and are often overturned, which corroborates the results of this study. Therefore, in addition to education, psychological support is also necessary for terminal cancer patients to make an independent and informed decision. Moreover, it is necessary to develop intervention techniques to provide psychological support.

Second, "making choices to protect everyone", as identified in this study, indicates that decisions on life-sustaining treatment pertain to the patient's whole family in addition to themselves. Participants wanted their last moments to be comfortable and to maintain dignity, and they did not want to forcefully pro- 
long a painful life. In addition, the participants in part based their decisions on life-sustaining treatment on not wanting to impose any burdens on their families. In a study of the experiences of terminal patients' families with decisions on lifesustaining treatment [18], similar categories were identified, such as the family's wish for a dignified death and burnout of the family related to care efforts. These findings show some similarities with the results of this research.

Third, "accepting and preparing for death" indicates that patients tended to eventually accept their mortality and make preparations for their deaths. Acceptance of death entailed patients recognizing mortality as a natural process in life, which is similar to the results of a study by Kim et al. [18], in which the families of terminal patients were able to accept the death sentence given by medical staff. If making a decision on lifesustaining treatment helps patients to patients can properly accept the fact that they are dying, their quality of during the remainder of their time may improve, as they can respond more appropriately to their health situation [19]. Therefore, an intermediary approach is needed in which medical staff not only provide terminal patients with policy information about decisions on life-sustaining treatment, but also education on acceptance and preparation for death so that patients can be ready to face their last moments with dignity. However, up to this point, education about life-sustaining treatment decisions has only included a simple introduction to policy measures [20]. Thus, additional content about accepting and preparing for death should be included in the future when providing education to terminal patients.

Fourth, "feeling distress" illustrates that patients who made decisions on life-sustaining treatments still struggle with concerns about departing from their children as they get closer to death. According to a study on the aging experiences of poor elderly people [21], Korean seniors felt guilt and regret when death prevented them from continuing to support their children, which they often viewed as their role as parents. Based on these findings, experiences like guilt surrounding children and wishing for their children's well-being may be understood in the context of Korea's Confucian culture centered around family values. These concerns about children may be related to anxiety about death. Thus, incorporating communication with terminal patients' families into intervention strategies about decisions on life-sustaining treatment could have a positive impact on mitigating anxiety about death.

Fifth, "pursuing spiritual well-being" demonstrates that participants did not lose hope in their recovery even after receiving a terminal diagnosis and withholding or withdrawing from life-sustaining treatment, and they tended to rely on their faith to overcome the fear of death and pain. A previous study also reported similar findings in which patients expecting death pursued spiritual well-being [22]. The results of this study align with the results of Tae [23], who argued that patients' hopes for potential recovery became active in a crisis and persisted until the very last moment. Another study that explored the impact of religion on Korean adults' attitudes toward decisions on life-sustaining treatment found that religious faith affected patients' views on death with dignity [24]. Therefore, education that emphasizes hope and spirituality should be included as a part of the intervention strategy for facilitating decisions on life-sustaining treatment.

Sixth, "evaluating the new system" is the thematic cluster encompassing patients' expressions of sympathy toward the need for policies about decisions on life-sustaining treatment, as well as frustration about encountering these new policies. Most participants sympathized with the intentions of the new policies and had a high regard for the state's efforts to implement a new policy, making positive remarks. However, many participants expressed frustration regarding their lack of sufficient understanding and education. Therefore, the new policy needs to be promoted to improve public understanding of it, and helpful educational intervention strategies should be implemented for terminal patients who are at the decisionmaking stage.

In conclusion, in the process of making decisions on lifesustaining treatment, cancer patients made their choices with heavy hearts, facing death due to a terminal diagnosis, and wanted to protect their dignity and their family. At the same time, terminal patients also accepted their mortality and prepared for death and experienced distress about their impending departure from their children. However, patients simultaneously pursued spiritual well-being to find peace within themselves. In addition, they assessed and evaluated the policies pertaining to decisions on life-sustaining treatment which they were encountering for the first time. Thus, terminal cancer 
patients require educational interventions to facilitate their decision-making process when making decisions on life-sustaining treatment, and the findings from this study suggest that concepts that should be emphasized in such interventions are acceptance and preparation for death, communication with the family, hope, and spiritual well-being.

This study made a meaningful stride in suggesting directions for nursing interventions related to decisions on life-sustaining treatment targeted to terminal cancer patients. Based on the above findings, this study makes the following two suggestions. First, it is necessary to identify important concepts with which to educate terminal cancer patients to help with decisions on life-sustaining treatment. Second, it is necessary to develop and conduct educational interventions to guide terminal cancer patients when making decisions on life-sustaining treatment.

\section{CONFLICT OF INTEREST}

No potential conflict of interest relevant to this article was reported.

\section{SUPPLEMENTARY MATERIALS}

Supplementary materials can be found via https://doi. org/10.14475/jhpc.2021.24.2.97.

\section{REFERENCES}

1. Korean Statistical Information Service [Internet]. Statistics of birth and death in the population survey. Daejeon: KOSIS; c2017 [cited 2020 Feb 20]. Available from: https://kosis.kr/statisticsList/statisticsListlndex.do? menuld=M_01_01 \&vwcd=MT_ZTITLE\& parmTabld=M_01_01\# SelectStatsBoxDiv.

2. Jung ST. A literary review of the law about Hospice Palliative Care and the Life-Sustaining Treatment Decision System for Patients in the Dying Process. Journal of the Korean Academy of Health and Welfare for Elderly 2016;8:145-71.

3. Korea National Institute for Bioethics Policy [Internet]. Seoul: KoNIBP; c2020 [cited 2020 Feb 20]. Available from: https://www.Ist.go.kr/ main/main.do.

4. Ministry of Government Legislation. Act on hospice and palliative care and decisions on life-sustaining treatment for patients at the end of life [Internet]. Sejong: Ministry of Government Legislation; c2016 [cited 2019 Jan 2]. Available from: https://www.lst.go.kr/decn/contentDetail.do? pgNo=1 \& cate $=$ \& searchOption $=0$ \&search Text $=\& b n o=1031$.

5. Bioethics Policy Research Center. Survey on withdrawal of life-sustaining treatment and advanced directives. Seoul:Bioethics Policy Research Center;2011. p. 8.

6. Hussey PS, Wertheimer S, Mehrotra A. The association between health care quality and cost: a systematic review. Ann Intern Med 2013;158:27-34.

7. Lee MH, Park YH. Factors influencing attitude toward advance directives of older cancer patients. J Korean Acad Adult Nurs 2015;27:449-58.

8. Hwang HY, Yang SJ. A comparative study on the perceptions of elderly patients and their caregivers toward life-sustaining treatment. Korean J Med Ethics 2016;19:484-503.

9. Chang WK, Ahn KJ, Kim MY, Kim YK, Han YJ. The role of a patient's family when the withdrawal of life-sustaining treatment is expected: a narrative analysis. Korean J Med Ethics 2015;18:172-89.

10. Colaizzi PF. Psychological research as a phenomenologist views it. In: Valle RS, King M, Eds. Existential-phenomenological alternative for psychology. New York:Oxford University Press;1978.

11. McConnell-Henry T, Chapman Y, Francis K. Husserl and Heidegger: exploring the disparity. Int J Nurs Pract 2009;15:7-15.

12. Guba EG, Lincoln YS. Effective evaluation: improving the usefulness of evaluation results through responsive and naturalistic approaches. San Francisco:Jossey-Bass Publishers;c1981. p. 1-444.

13. Sandelowski M. The problem of rigor in qualitative research. ANS Adv Nurs Sci 1986;8:27-37.

14. Chang WK, Ahn KJ, Kim MY, Kim YR, Han YJ. The role of a patient's family when the withdrawal of life-sustaining treatment is expected: A narrative analysis. Korean J Med Ethics 2015;18:172-89.

15. Hickman RL Jr, Daly BJ, Lee E. Decisional conflict and regret: Consequences of surrogate decision making for the chronically critically ill. Appl Nurs Res 2012;25:271-5.

16. Park EY. The experience of family members on deciding to withdraw life-sustaining treatment for patients who are terminally ill [dissertation]. Seoul: Yonsei Univ.; 2003. Korean.

17. Brehaut JC, O'Connor AM, Wood TJ, Hack TF, Siminoff L, Gordon E, et al. Validation of a decision regret scale. Med Decis Making 2003;23:281-92. 
18. Kim MH, Kang EH, Kim MY. Family decision-making to withdraw life-sustaining treatment for terminally-ill patients in an unconscious state. Korean J Hosp Palliat Care 2012;15:147-54.

19. Nyatanga B. Knowledge of impending death and its effect on quality of dying. Br J Community Nurs 2015;20:152.

20. Kang JS, Kim HO. The effect of video education on cancer patient advance directive writing. Asian Oncol Nurs 2020;20:39-49.

21. Chang KE. A phenomenological study on the lived experience of aging of the poor elderly. Korean Acad Soc Welf 2009;61:355-80.

22. Kim YS, Tae YS, Nam KH, Kim HY. The experience of uncertainty in cancer patients undergoing chemotherapy. Asian Oncol Nurs 2018;18:115-26.

23. Tae YS. Hope phenomen of Korean cancer patients [dissertation]. Seoul: Ewha Womans Univ.;1995. Korean.

24. Shin E. Effect of religiosity on life-sustaining care and death with dignity among Korean adults. Won-Buddhist Thought \& Religious Culture 2019;79,247-81. 